\title{
Identification of Sperm mRNA Biomarkers Associated with Sex-Determination in Korean Native Cows
}

\author{
Kwan-Sik Min ${ }^{1,2, *}$, Munkhzaya Byambaragchaa ${ }^{1}$, Hyun Kim $^{3}$ and Myung-Hum Park ${ }^{3}$ \\ ${ }^{1}$ Animal Biotechnology, Graduate School of Future Convergence Technology, Anseong 17579, Korea \\ ${ }^{2}$ Department of Animal Life Science, Institute of Genetic Engineering, Hankyong National University, Anseong 17579, \\ Korea \\ ${ }^{3}$ TNT Research, Anyang 14059, Korea
}

Received June 18, 2019

Revised June 25, 2019

Accepted June 27, 2019

\author{
*Correspondence \\ Kwan-Sik Min \\ Animal Biotechnology, Graduate School of \\ Future Convergence Technology, Hankyong \\ National University, 327 Joongang-ro, \\ Anseong 17579, Korea \\ Tel: +82-31-670-5421 \\ Fax: +82-31-670-5616 \\ E-mail: ksmin@hknu.ac.kr \\ ORCID \\ https://orcid.org/0000-0002-5451-3085
}

\begin{abstract}
This study was conducted to analyze the specific genes associated with sex-determination in Korean native cow. The highly organized spermatogenesis requires accurate spatial and temporal regulation of gene expression, which is governed by transcriptional, post-transcriptional, and epigenetic processes. Recently, farmers have been interested in determining the sexual identity of the calves in their farm. We analyzed the sperm of Korean native and Holstein cows, which were supplied from Hanwoo Improvement Center. We evaluated sperm motility and expression of sperm-specific genes after treating semen with both male- and female reagents. Sperm motility in Korean native cows decreased by approximately $10 \%$ in the first 30 minutes after treatment with sex-determination reagent. However, sperm motility of Holstein cows decreased to $60-70 \%$ after 15 minutes and to $20-30 \%$ after 30 minutes. We selected six specific genes expressing in the spermatozoa to analysis the gene expression level. The Real-time PCR results suggest that the selected genes (Gimap4, Tmeff1, Rac2, Abi2, Rac1, and Clu) were highly expressed in the group treated with the male reagent compared to the group treated the female reagent and to the untreatedgroup (control). In the present study, we suggest that the selected genes play a pivotal role in sex-determination.
\end{abstract}

Keywords: Korean native cows, sex-determinant reagent, sperm mRNA

\section{INTRODUCTION}

Sex determination (male fertility) depends on the successful and constant process of of spermatogenesis, which is a highly organized process where spermatozoa develop from germ cells in the seminiferous tubules of the testis (Chen et al., 2017). The testis is one of many organs routinely and systematically assessed in comparative preclinical drug studies (Dere et al., 2017). DNA damage to sperm cells has been identified as a major contributor to male infertility and to negative outcomes following assisted reproduction treatment, including impaired embryo development and birth defects in the offspring (Ebner et al., 2011; Zribi et al., 2011). However, conventional semen analysis does not measured all parameters related to sperm quality (Cissen et al., 2016). Several papers have investigated the link between pregnancy failure and DNA damage to sperm cells (Ozmen et al., 2007; Lin et al., 
2008;). Thus, DNA integrity of sperm cells is one of the key determinants of successful fertilization and embryo development (Robinson et al., 2012). Sperm with DNA damage caused by specific reagents are capable of fertilizing eggs (Aitken et al., 1998; Gandini et al., 2004), but may be associated to low pregnancy rates (Bungum et al., 2007; Collins et al., 2008; Frydman et al., 2008; Lin et al., 2008).

These technique for sex-determination relies on flow cytometric assays that separates spermatozoa bearing $\mathrm{X}$ and $\mathrm{Y}$ chromosome with an accuracy greater than $90 \%$ (Garner et al., 1983; Morrell et al., 1988). However, it is expensive, time-consuming (Seidel, 2003), and accelerates changes in mRNA expression levels of certain genes in the embryo (Morton et al., 2007), which yields lower fertility rates in vitro (Lu et al., 1999; Xu et al., 2009) and in vivo (Maxwell et al., 2003; Bodmer et al., 2005). Recently, many methods to isolate sperm have been developed using PCR (Tan et al., 2008), such as DNA quantification of sex sorted sperm (Welch and Johnson, 1999), fluorescence in site hybridization (Rens et al., 2001), real-time quantitative PCR (qPCR) (Joerg et al., 2004), and SYBR green qRT-PCR (Husna et al., 2016).

In order to determine the sexual identity of Korean native cows, we investigated sperm motility in semen treated with specific sex-determination reagents. We also analyzed the expression level of sperm mRNA in semen treated with male and female reagents.

\section{MATERIALS AND METHODS}

\section{Experimental design}

Frozen semen of Korean native and Holstein cows was obtained from the Hanwoo Improvement Center-Semen Production Unit. For both breeds, semen was divided into three groups. Cryopreserved treated and untreated (control) semen samples were analyzed for sperm motility after thawing for 0, 15 minutes, and 30 minutes. Sperm was then collected and stored at $-80^{\circ} \mathrm{C}$.

\section{Primer design}

A pair of specific primers were designed for GTPase immunity-associated protein family member4 (Gimap4), a transmembrane protein containing two follistatin and an epidermal growth factor-like (EGF) region (Tmeff1), Rac1, Rac2, abi-interactor 2 (Abi2), and clusterin (Clu), all known as sperm specific genes in cattle. According to the parameters required for the SYBR green real-time PCR, the NCBI dataset was used. An internal housekeeping gene (GAPDH) was needed as a positive control. Gene sequences of the forward and reverse primers are shown in Table 1.

\section{Sperm motility after reaction with sex-determination reagent}

Frozen semen' straws of Korean native (KPN 998) and Holstein (334) cows were thawed for 20-25 seconds in a water bath at $37^{\circ} \mathrm{C}$. Semen was then put into 6 or 12 -well plates, and female and male reagents bought from TNT research (Anyang, Korea) were added to each sample (each well). After which, semen was incubated for 0,15 , and 30 minutes at room temperature. Sperm motility of each sample was objectively analyzed with a microscope by two researchers. After sperm motility was evaluated, RNA was extracted from samples. The sperm motility was analyzed in triplicate independent repeats by two researchers.

\section{RNA isolation of sperm and qRT-PCR}

After samples were treated with the specific reagents, sperm was collected and placed in $1.5 \mathrm{~mL}$ tubes. Following centrifugation for five minutes at $2,000 \times \mathrm{g}$, the pellet

Table 1. Specific primers used to amplify genes of Korean native cows

\begin{tabular}{clc}
\hline Gene & \multicolumn{1}{c}{ Sequence $\left(\mathbf{5}^{\prime} \rightarrow \mathbf{3}^{\prime}\right)$} & Length $(\mathrm{bp})$ \\
\hline bClus & & \\
Forward & tca gca ggc tgt acg acc agc tg & 317 \\
Reverse & tc cgg cgg tat tgc tgc agt gct & \\
bGIMAP4 & & \\
Forward & ctc tca agg aga tta ccc gct gca & 412 \\
Reverse & gc tct gta ata ttc ttg taa cac & \\
bTMEFF1 & \\
Forward & atg atg gac tac agt atc gac cag & 314 \\
Reverse & ggt tat gca cat gac aat tgc tac & \\
bABI2 & & \\
Forward & gta cca aat gat tac gta cct agc & 254 \\
Reverse & at tca tgc tgt aga act gaa cag & \\
bRAC1 & & \\
Forward & tgt cct acc cgc aga cag atg tat & 261 \\
Reverse & agc gcc gag cac tcc agg tat & \\
bGAPDH & & \\
Forward & acc act gtc cac gcc atc act & 452 \\
Reverse & tcc acc acc ctg ttg ctg ta &
\end{tabular}


of sperm was saved and the supernatant centrifuged again for three minutes at 2,000 $\times \mathrm{g}$ (Pacheco et al., 2012), the pellets were incubated in a lysis buffer $(0.15 \mathrm{M}$ ammonium chloride, $10 \mathrm{mM}$ potassium bicarbonate, and 0.1 mM EDTA (Thermo Fisher Scientific Inc.,) for 30 seconds prior to centrifugation at $16,000 \times \mathrm{g}$ for one minutes to remove contaminants, leaving the sperm intact. RNA was extracted from the samples using the Trizol reagent (Invitrogen) and the mirVana miRNA Isolation kit (Applied Biosystems/Ambion, TX). RNA purity was confirmed by the absence of $18 / 28$ S ribosomal RNA peaks with an UV spectrophotometer (Biorad). Sperm mRNA content was assessed using qRT-PCR arrays. The qRT-PCR reaction followed the manufacturer's instructions using an ABI 7900 HT thermocycler (Applied Biosciences, Life Technologies Corporation, $\mathrm{CA}$ ). Raw $\mathrm{C}_{\mathrm{t}}$ values were normalized to the geometric mean of the housekeeping gene (GAPDH). $\mathrm{C}_{\mathrm{t}}$ values and $\mathrm{C}_{\mathrm{t}}$ expression were analyzed using the $\Delta \Delta \mathrm{C}_{\mathrm{t}}$ method following ABI's guidelines. The fold change ratio range was generated using the formula $2^{-\Delta \Lambda}$, the standard error of the treatment groups was generated after calculating the average $\Delta \mathrm{C}_{\mathrm{t}}$ values.

\section{Statistic analysis}

Sperm mRNA transcript data was analyzed using oneway ANOVA to identify significant changes relative to vehicle control. The analysis was carried out in Prism 6 software (GraphPad Software, CA).

\section{RESULTS}

Semen samples treated with male and female reagents are shown in Fig. 1. The upper lanes refer to the control group, the second lane refer to samples treated with the male reagent, and the third lane to samples treated with female reagent (Fig. 1). Sperm motility of Korean native and Holstein breeds after being treated with the corresponding reagent are shown in Table 2 . In samples treated with the specific reagents, sperm motility of Korean native cows was $80,70-80$, and $70-75 \%$ at 0,15 , and 30 minutes, respectively. Sperm motility of Korean

Table 2. Sperm motility of Korean native and Holstein cows in each treatment group

\begin{tabular}{lcccc}
\hline \multirow{2}{*}{ Treatment Groups } & \multicolumn{3}{c}{ Treatment time and motility (\%) } \\
\cline { 3 - 5 } & & 0 min & 15 min & 30 min \\
\hline Korean native & Control & 80 & $75-80$ & $75-80$ \\
& & 80 & $75-80$ & $75-80$ \\
& Female & $75-80$ & $70-75$ & $70-75$ \\
& & 80 & $75-80$ & $70-75$ \\
& Male & 80 & $75-80$ & $70-75$ \\
& & 80 & $75-80$ & $70-75$ \\
Holstein & Control & $75-80$ & $60-70$ & 30 \\
& & 80 & $60-70$ & 40 \\
& Female & 80 & $60-70$ & $20-30$ \\
& & $75-80$ & $60-70$ & $20-30$ \\
& Male & $75-80$ & $50-60$ & 30 \\
& $75-80$ & $50-60$ & $20-40$ \\
\hline
\end{tabular}

The sperm motility was analyzed in triplicate independent repeats as described in the Material and Methods.
A

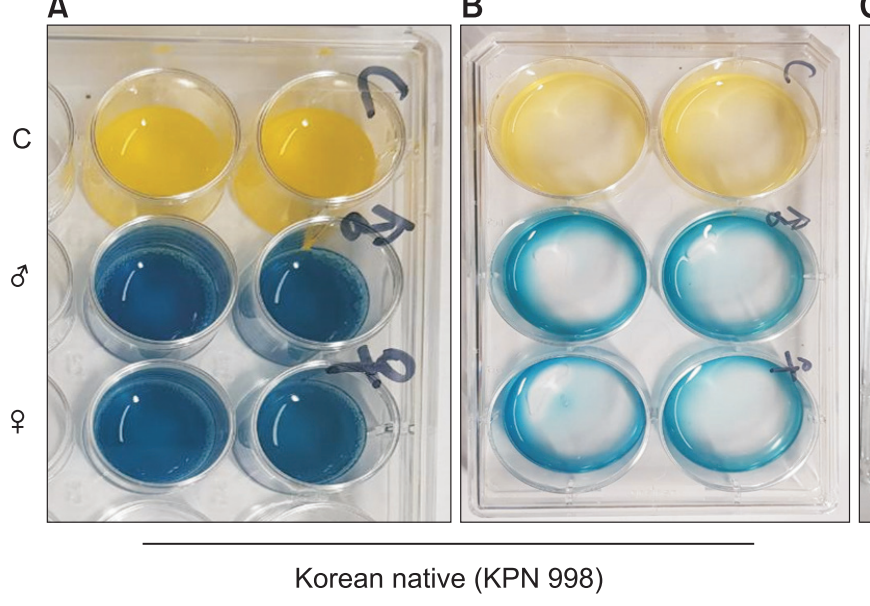

C

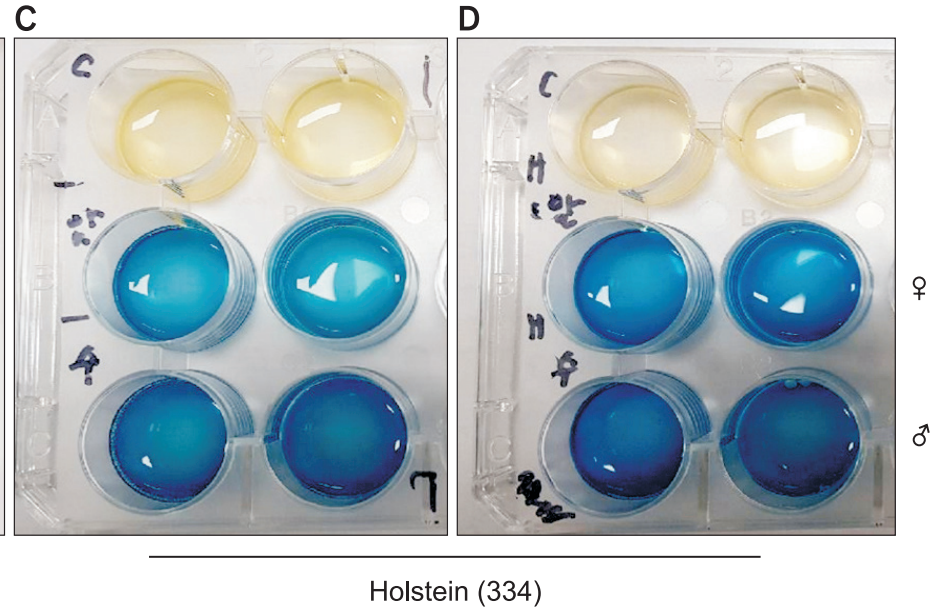

Fig. 1. Reaction of semen with male and female reagents in Korean native Cattle and Holstein. (A) and (B) are shown the Korean Native Cattle. (C) and (B) are shown the Holstein. These images were taken 30 minutes after the corresponding reagents were added. C: control. 
native cows decreased after 30 minutes of thawing in all samples, including the control group where sperm motility decreased by $15 \%$. However, sperm motility of Holstein cows was even lower, decreasing to $20-40 \%$ after 30 minutes (Table 2).

Sperm mRNA transcript levels on the qRT-PCR array panel was significantly greater in sperm treated with the male reagent (Fig. 2). Interestingly, transcript level of RAC1, Abi2, Tmeff1, GIMP4, and Clu observed significantly different 30 minutes after reagents were added. When treated with the male reagent, transcript levels of Rac1, abi2, Tmeff1, and Clu were significantly greater in comparison to the control group. Transcript levels of $\mathrm{Clu}$ were 5 times greater when treated with the male reagent in comparison to the female reagent. Transcript levels of the other genes were just a 1.2 to 1.8 times greater when treated with the male reagent in comparison to the female reagent.

\section{DISCUSSION}

Sexed semen has brought an economic advantages to the dairy industry to Korean native cattle farms. Isolation sperm in order to separate $\mathrm{X}$ and $\mathrm{Y}$ chromosomes has been widely studied. Sperm with higher motility (Henkel and Schill, 2003) and viability (Lucio et al., 2012) is effective in increasing fertilization success (Rens et al., 2004). However, isolating sperm too expensive. Thus we tested

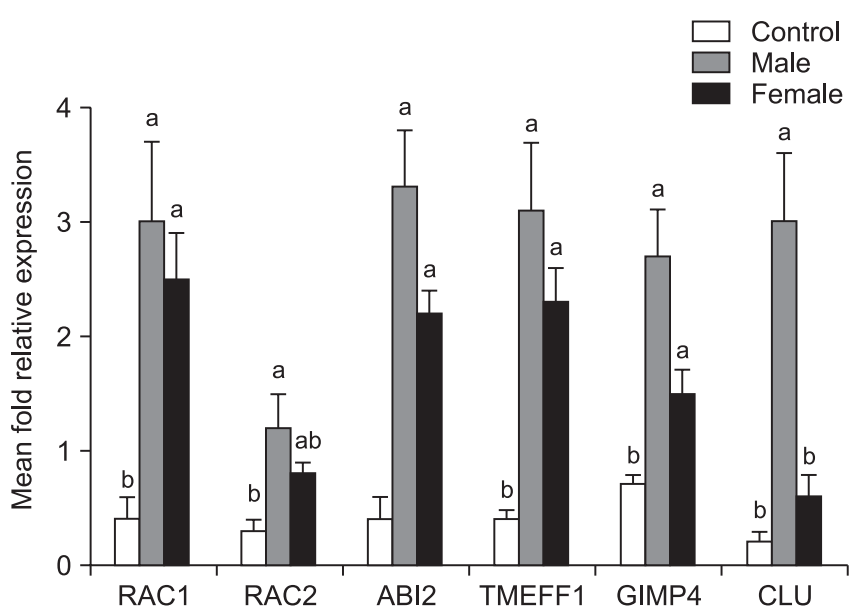

Fig. 2. Expression level of mRNA transcription following treatment with the corresponding sex determination reagent for 30 minutes. Data are expressed as the mean ratio relative to the vehicle control \pm SEM. sex-determination reagents that have been developed without having to isolate sperm. Our results show that sperm motility in Korean native cows was hardly affected by these reagents, suggesting that the sperm is capable to fertilize eggs, both in vitro and in vivo. However, sperm motility of Holstein semen decreased significantly. The best semen storage method, deep-freezing or stocking in LN2 tank, remains unclear.

The real-time PCR technique is considered a valid, accurate and reliable method to quantity spermatozoa bearing $\mathrm{X}$ and $\mathrm{Y}$ chromosomes in bovine semen (Maleki et al., 2013; Husna et al., 2017). In this studies, we used qRTPCR to analyze six specific genes (Gimap4, Tmeff1, Rac1, Rac2, abi2, and Clu) that are involved with important functions of spermatogenesis. Changes in sperm mRNA include increased gene expression in sperm treated with the male reagent.

$\mathrm{Clu}$ is a glycoprotein involved in many biological processes that affects germ cell maturation (Anton and Krawetz, 2012). Clu, which is also secreted by sertoli cells, maintains the homeostatic balance between cell viability and proliferation (Ammar and Closset, 2008). Clu mRNA was detected in rat and pig spermatozoa and mRNA levels were greater in testis exposed to methoxychlor (Ostermeier et al., 2004; Vaithinathan et al., 2009). Gimap4 is involved in accelerating programmed T-cell death (Schnell et al., 2006) and interacts with the trans-Golgi network to facilitate the proper development of sperm acrosomes (Escalier et al., 1991; Heinonen et al., 2015). Thus, Gimap4 is very important as it positively affects the quality of sperm (Dere et al., 2017). Tmeff1 has been reported to be highly expressed in human embryos and nerve tissues (Condomines et al., 2009) and was initially found with differential expression in brain tissues and brain tumors (Eib and Martens, 1996). The expression of Tmeff1 in an ovarian cancer cells was downregulated after the inhibition of p53 (Nie et al., 2019). Thus, the function of Tmeff 1 in the sperm is not well known.

Recently, Abi1 and Abi2 interact with and dephosphorylate brassinosteroid insentitive2 (BIN2) to regulate its activity toward the phosphorylation of bri1-EMS-Suppressor1 (BES1) in the Abi2 (Wang et al., 2018). The genetic and molecular functions for sperm motility in Abi1 and $\mathrm{Ab} 2$ were not reported until now. Rac2, a member of the Rho small-GTPase family, is restricted to the hematopoietic lineage, which plays a principal role in regulat- 
ing the actin cytoskeleton and neutrophil biology (Hsu et al., 2017). Rac2 is required for adhesion and retention of neutrophils in the hematopoietic tissue, yet not required for their release from this tissue (Deng et al., 2011).

Our study has demonstrated that Clu, Tmeff 1 and Gimap4 play a key role in the male determination of bovine sperm. In the present study, we suggest that these genes play a key role in sperm bearing $\mathrm{Y}$ chromosomes. These genes may be used as bio-marker to determine sex in bovine sperm. The reagent used in the present study is adequate and may be used to produce male and female calves in bovine farms, suggesting that these genes could be a new bio-maker for sex-determination in bovine.

\section{CONFLICTS OF INTEREST}

No potential conflict of interest relevant to this article was reported.

\section{ACKNOWLEDGEMENTS}

This research was financially supported by the Institute of Planning and Evaluation for Technology program (81703-2-HD020) Ministry of Agriculture, Food and Rural Affairs, Republic of Korea.

\section{ORCID}

Kwan-Sik Min: https://orcid.org/0000-0002-5451-3085 Munkhzaya Byambaragchaa: https://orcid.org/0000-0002-0277-1816 Hyun Kim: https://orcid.org/0000-0001-5540-2857 Myung-Hum Park: https://orcid.org/0000-0002-7920-4756

\section{REFERENCES}

Aitken RJ, Gordon E, Harkiss D, Twigg JP, Milne P, Jennings Z and Irvine DS. 1998. Relative impact of oxidative stress on the functional competence and genomic integrity of human spermatozoa. Biol. Reprod. 59:1037-1046.

Ammar H and Closset JL. 2008. Clusterin activates survival through the phosphatidylinositol 3-kinase/Akt pathway. J. Biol. Chem. 283:12851-12851.

Anton E and Krawetz SA. 2012. Spermatozoa as biomarkers for the assessment of human male infertility and genotoxicity. Syst. Biol. Reprod. Med. 58:41-50.

Bodmer M, Janett F and Hassig M. 2005. Fertility in heifers and cows after low dose insemination with sex-sorted and non-sorted sperm under field conditions. Theriogenology 64:1647-1655.
Bungum M, Humaidan P, Axmon A, Spano M, Bungun L, Erenpriess J and Giwercman A. 2007. Sperm DNA integrity assessment in prediction of assisted reproduction technology outcome. Hum. Reprod. 22:174-179.

Chen X, Li X, Guo J, Zhang P and Zeng W. 2017. The roles of microRNAs in regulation of mammalian spermatogenesis. J. Anim. Sci. Biotech. 8:35.

Cissen M, van Wely M, Scholten I, Mansell S, Bruin JPd, Mol BW, Braat D, Repping S and Hamer G. 2016. Measuring sperm DNA fragmentation and clinical outcome of medically assisted reproduction: A systematic review and metaanalysis. PLoS ONE 11(11):e0165125.

Collins JA, Barnhart KT and Schlegel PN. 2008. Do sperm DNA integrity tests predict pregnancy with in vitro fertilization? Fertil. Steril. 89:823-831.

Condomines M, Hose D, Rème T. 2009. Gene expression profiling and real-time PCR analyses identify novel potential cancer-testis antigens in multiple myeloma. J. Immunol. 183:832-840.

Deng Q, Yoo SK, Cavnar PJ, Green JM and huttenlocher A. 2011. Dual roles for Rac2 in neutrophil motility and active retention in zebrafish hematopoietic tissue. Dev. Cell 21:735-745.

Dere E, Spade DJ, Hall SJ, Altemus A, Smith JD, Phillips JA, Moffit JS, Blanchard KT and Boekelheide K. 2017. Identification of sperm mRNA biomarker associated with testis injury during prelcinical testing of pharmaceutical compounds. Toxicology and Applied Pharmacolgy 320:1-7.

Ebner T, Shebl O, Moser M, Mayer TB, Arzt W and Tews G. 2011. Easy sperm processing technique allowing exclusive accumulation and later usage of DNA-strandbreak-free spermatozoa. Reprod. Biomed. 22:37-43.

Eib DW, Martens GJ. 1996. A novel transmembrane protein with epidermal growth factor and follistatin domains expressed in the hypothalamohypophysial axis of Xenopus laevis. J. Neurochem. 67:1047-1055.

Escalier D, Gallo JM, Albert M, Meduri G, Bermudez D, David G and Schrevel J. 1991. Human acrosome biogenesis: immunodetection of proacrosin in primary spermatocytes and of its partitioning pattern during meiosis. Development 113:779-788.

Fryman N, Prisant N, Hesters L, Fryman R, Tachdjian G, Cohen-Bacrie P and Fanchin R. 2008. Adequate ovarian follicular status does not prevent the decrease in pregnancy rates associated with high sperm DNA fragmentation. Fertil. Steril. 89:92-97.

Gandini L, Lombardo F, Paoli D, Caruso F, Eleuteri P, Leter G, Ciriminna R, Culasso F, Dondero F and Lenzi A. 2004. Fullterm pregnancies achieved with ICSI despite high levels of sperm chromatin damage. Hum. Reprod. 19:1409-1417.

Garner DL, Gledhill BL, Pinkel D, Lake S, Stephenson D and Van Dilla MA. 1983. Quantification of the X and Y chromosome-bearing spermatozoa of domestic animals by flow cytometry. Biol. Reprod. 28:312-321.

Heinonen MT, Kanduri K, Lahdesmaki HJ, Lahesmaa R and Henttinen TA. 2015. Tubulin- and actin-associating GIMAP4 
is required for INF-tau secretion during T-cell differentiation. Immunol. Cell Biol. 93:158-166.

Henkel RR and Schill WB. 2003. Sperm preparation for ART. Reprod. Biol. Endocrinol. 1:108.

Hsu AY, Wang D, Gurol T, Zhou W, Zhu X, Lu HY and Deng Q. 2017. Overexpression of microRNA-722 fine-tunes neutrophilic inflammation by inhibiting Rac2 in zebrafish. Disease Models and Mechanisms 10:1323-1332.

Husna AU, Ejaz R, Qadeer S, Azam A, Rakha BA, Ansari MS, Shahzad Q, Javed M, Vazquez-Levin MH and Akhter S. 2016. A comparative analysis of sperm selection procedures prior to cryopreservation for Nili-Ravi buffalo bull (Bubalus bubalis) semen-: Assessment of its impact on post-thaw sperm functional quality. Anim. Reprod. Sci. 174:29-36.

Joerg H, Asai M, Graphodatskaya D, Janett F and Stranzinger G. 2004. Validating bovine sexed semen samples using quantitative PCR. J. Anim. Breed. Genet. 121:209-215.

Lin MH, Kuo-Kuang LR, Li SH, Lu CH, Sun FJ and Hwu YM. 2008. Sperm chromatin structure assay parameters are not related to fertilization rates, embryo quality, and pregnancy rates in in vitro fertilization and intracytoplasmic sperm injection, but might be related to spontaneous abortion rates. Fertil. Steril. 90:352-359.

Lu KH, Cran DG and Seidel Jr GE. 1999. In vitro fertilization with flow-cytometrically-sorted bovine sperm. Theriogenology 52:1393-1405.

Lucio AC, Resende MV, Demowseck-Meirelles, JA, Perini AP, Oliveira IZ, Miguel MCV, Carmo AS, Tomita SY, Alves BCA, Fazano FAT and Lima VFMH. 2012. Assessment of swim-up and discontinuous density gradient in sperm sex preselection for bovine embryo production. Arq. Bras. Med. Vet. Zootec. 64:525-532.

Maleki AF, Moussavi ARH, Nassiri MR, Tahmoorespur M and Vakili SA. 2013. Introducing and validation of SYBR Green Real-Time PCR method to determinate sex ratio in bovine semen. Anim. Reprod. Sci. 140:1-6.

Maxwell WMC, Hollinshead FK and Rath D. 2003. Effect of dose of sperm processed for sex-sorting and cryopreservation on fertility in ewes. Theriogenology 59:511.

Morrell JM, Keeler KD, Noakes DE, Mackenzie NM and Dresser DW. 1988. Sexing of sperm by flow cytometry. Vet. Rec. 122:322-324.

Morton KM, Herrmann D, Sieg B, Struckmann C, Maxwell WMC, Rath D, Evans G, Lucas-Hahn A, Niemann H and Wrenzycki C. 2007. Altered mRNA expression patterns in bovine blastocysts after fertilisation In vitro using flow- cytometrically sex-sorted sperm. Mol. Reprod. Dev. 74:931940.

Nie X, Liu C, Guo Q, Zheng MJ, Gao LI, Li X, Liu DW, Zhu LC, Liu JJ and Lin B. 2019. TMEFF1 overexpression and its mechanism for tumor promotion in ovarian cancer. Cancer Manag Res. 11:839-855.

Ostermeier GC, Dix DJ, Miller J, Khatri P and Krawetz SA. 2002. Spermatozoal RNA profiles of normal fertile men. Lancet 360:772-767.

Ozmen B, Caglar GS, Koster F, Schopper B, Diedrich K and AIHasani S. 2007. Relationship between sperm DNA damage, induced acrosome reaction and viability in ICSI patients. Reprod. Biomed. 15:208-214.

Pacheco SE, Andrson LM, Sandrof MA, Vantangoli MM, Hall SJ, Boekelheide K. 2012. Sperm mRNA transcripts are indicator of sub-chronic low dose testicular injury in the fisher 344 rat. Plos ONE 7(8):e44280.

Rens SS, Sun CH, Ku CH, Chen DC and Wu GJ. 2004. Comparison of four methods for sperm preparationfor IUI. Archandrology 50:139-143.

Robinson L, Gallos ID, Conner SJ, Rajkhowa M, Miller D, Lewis S, Kirkman-Brown J and Coomarasamy A. 2012. The effect of sperm DNA fragmentation on miscarriage rates: a systematic review and meta-analysis. Human Reprod. 27:29082917.

Seidel Jr GE. 2003. Sexing mammalian sperm-intertwining of commerce, technology, and biology. Anim. Reprod. Sci. 79:145-156.

Vaithinathan S, Saradha B and Mathur PP. 2009. Methoxychlorinduced alteration in the levels of HSP70 and clusterin is accompanied with oxidative stress in adult rat testis. J. Biochem. Mol. Toxicol. 23:29-35.

Wang H, Tang J, Liu J, Hu J, Liu J, Chen Y, Cai Z and Wang X. 2018. Abscisic acid signaling inhibits brassinosteroid signaling through dampending the dephosphorylation of BIN2 by ABI1 and ABI2. Mol. Plant 11:315-325.

Welch GR and Johnson LA. 1999. Sex pre selection: laboratory validation of the sperm sex ratio of flow sorted $\mathrm{X}$ and $\mathrm{Y}$ sperm by sort reanalysis for DNA. Theriogenology 52:13431352.

Xu J, Chaubal SA and Du F. 2009. Optimizing IVF with sexed sperm in cattle. Theriogenology 71:39-47.

Zribi N, Chakroun NF, Elleuch H, Abdallah FB, Ben Hamida AS, Gargouri J, Fakhfakh FF and Keskes LA. 2011. Sperm DNA fragmentation and oxidation are independent of malondialdhyde. Reprod. Biol. Endorinol. 9:1-8. 